\title{
NIF effects of illuminance and correlated color temperature of office light on alertness, mood, and performance across cognitive domains
}

Citation for published version (APA):

Ru, T., de Kort, Y. A. W., Smolders, K. C. H. J., Chen, Q., \& Zhou, G. (2019). NIF effects of illuminance and correlated color temperature of office light on alertness, mood, and performance across cognitive domains. Building and Environment, 149, 253-263. https://doi.org/10.1016/j.buildenv.2018.12.002

DOI:

10.1016/j.buildenv.2018.12.002

Document status and date:

Published: 01/02/2019

Document Version:

Accepted manuscript including changes made at the peer-review stage

Please check the document version of this publication:

- A submitted manuscript is the version of the article upon submission and before peer-review. There can be important differences between the submitted version and the official published version of record. People interested in the research are advised to contact the author for the final version of the publication, or visit the DOI to the publisher's website.

- The final author version and the galley proof are versions of the publication after peer review.

- The final published version features the final layout of the paper including the volume, issue and page numbers.

Link to publication

\footnotetext{
General rights

- You may freely distribute the URL identifying the publication in the public portal. follow below link for the End User Agreement:

www.tue.nl/taverne

Take down policy

If you believe that this document breaches copyright please contact us at:

openaccess@tue.nl

providing details and we will investigate your claim.
}

Copyright and moral rights for the publications made accessible in the public portal are retained by the authors and/or other copyright owners and it is a condition of accessing publications that users recognise and abide by the legal requirements associated with these rights.

- Users may download and print one copy of any publication from the public portal for the purpose of private study or research.

- You may not further distribute the material or use it for any profit-making activity or commercial gain

If the publication is distributed under the terms of Article $25 \mathrm{fa}$ of the Dutch Copyright Act, indicated by the "Taverne" license above, please 


\section{Accepted Manuscript}

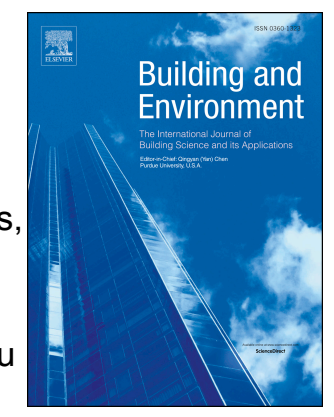

NIF effects of illuminance and correlated color temperature of office light on alertness, mood, and performance across cognitive domains

Taotao Ru, Yvonne A.W. de Kort, Karin C.H.J. Smolders, Qingwei Chen, Guofu Zhou

PII:

S0360-1323(18)30737-6

DOI: https://doi.org/10.1016/j.buildenv.2018.12.002

Reference: BAE 5835

To appear in: Building and Environment

Received Date: 15 August 2018

Revised Date: 30 November 2018

Accepted Date: 1 December 2018

Please cite this article as: Ru T, de Kort YAW, Smolders KCHJ, Chen Q, Zhou G, NIF effects of illuminance and correlated color temperature of office light on alertness, mood, and performance across cognitive domains, Building and Environment (2019), doi: https://doi.org/10.1016/j.buildenv.2018.12.002.

This is a PDF file of an unedited manuscript that has been accepted for publication. As a service to our customers we are providing this early version of the manuscript. The manuscript will undergo copyediting, typesetting, and review of the resulting proof before it is published in its final form. Please note that during the production process errors may be discovered which could affect the content, and all legal disclaimers that apply to the journal pertain. 


\title{
NIF effects of illuminance and correlated color temperature of office
}

\section{light on alertness, mood, and performance across cognitive domains}

\author{
Taotao Ru ${ }^{\text {a,b,c }}$ Yvonne A.W.de Kort ${ }^{\text {b }}$ Karin C.H.J. Smolders ${ }^{b}$ Qingwei Chen ${ }^{\text {a }}$ Guofu Zhou $^{\text {a,c }}$ \\ ${ }^{a}$ Lab of Light and Physiopsychological Health, National Center for International Research on Green \\ Optoelectronics, South China Normal University, Guangzhou 510006, China \\ ${ }^{\mathrm{b}}$ Human Technology Interaction, School of Innovation Sciences, \& Intelligent Lighting Institute, \\ Eindhoven University of Technology, Eindhoven, 5600mb, the Netherlands \\ ${ }^{\mathrm{c}}$ Guangdong Provincial Key Laboratory of Optical Information Materials and Technology \&Institute of \\ Electronic Paper Displays, South China Academy of Advanced Optoelectronics, SCNU, Guangzhou, \\ 510631, China
}

First corresponding author: Prof.dr.ir Yvonne de Kort

\section{y.a.w.d.kort@tue.nl}

Human Technology Interaction, School of Innovation Sciences, TU/e.P.o.BOX513,5600mb, the Nertherlands

Second corresponding author: Prof. Dr. Guofu Zhou

$$
\text { guofu.zhou@m.scnu.edu.cn }
$$

South China Academy of Advanced Optoelectronics, SCNU, Guangzhou, 510631, China 
1 Abstract:

2 Research has explored acute effects of light level and correlated color temperature (CCT) of indoor

3 lighting on subjective measures of alertness and task performance during daytime. Yet, these

4 investigations did not render a conclusive or consistent finding on the relative contribution of

5 illuminance and CCT on various cognitive domains. The current study $(\mathrm{N}=57)$ investigated diurnal effects of illuminance level (100 lx vs. $1000 \mathrm{~lx}$ at eye level) and correlated color temperature (3000 K vs.

7

$6500 \mathrm{~K})$ in a simulated office environment on subjective alertness and performance in sustained attention, response inhibition, conflict monitoring, and working memory. Moreover, effects on mood and appraisals were explored. The findings revealed that the high vs. low CCT manipulation elicited no statistically significant benefits on subjective alertness and task performance, but revealed an increase in negative affect. Exposure to high vs. low illuminance rendered subtle benefits on participants' mood and selectively improved performance. Reaction speed in the Go/No-go task and Flanker task (only incongruent trials) were significantly enhanced with $1000 \mathrm{~lx}$ compared to $100 \mathrm{~lx}$ lighting, but not statistically significant in the PVT task or the PVSAT task. Effects are discussed in consideration of task type and melanopic activation under the various light conditions.

Keywords: Lighting, Illuminance, Correlated color temperature; Alertness; Cognitive domain

\section{Introduction}

Since the discovery of the intrinsically photosensitive retinal ganglion cells (ipRGCs) in the human eye [1-4], an increasing number of studies have been performed to investigate the non-image forming (NIF) effects of ocular light exposure on human functioning during the biological night and day. Research has established that light does not only have the potential to produce phase-shifting effects on 
1 the human circadian rhythm, but can also exert instantaneous effects on physiological arousal, neural

2

activity, hormone production, and subjective alertness [5-14]. In addition, light has also been shown to impact cognitive ability [15-18], including attention [19-24], inhibitory control [11,25], and working memory [26-29].

Whereas nocturnal effects of light on alertness and performance may be attributed to melatonin suppression, this mechanism is not likely to underlie daytime effects, as circulating melatonin concentrations are generally negligible then [30,31]. Alternative explanations offered in the literature pertain to potential modulation of alertness and mood-related pathways (e.g., in brainstem, thalamus, amygdala and or hippocampus) [17,32-36]; or to psychological mechanisms including appraisal and motivation, beliefs or expectations regarding effects of blue(-eiriched) or bright light (e.g., $[18-20,37,38])$.

Light's effect on cognition is determined by many factors, chief among them are parameters of light (i.e., illuminance level and spectral composition), timing characteristics (exposure duration, time of day and year) as well as task type $[17,39]$. Previous studies on monochromatic light have established that the NIF effect of light on alertness is most pronounced at short wavelengths (i.e., about 460-480nm) $[10,17,29,40]$. But research employing polychromatic light has revealed rather inconsistent alerting and cognitive effects of exposure to varying levels or spectra of white light, especially during daytime $[16,18,19,27,36]$. In addition to properties of the light itself, research suggests that different cognitive tasks may also be differentially sensitive to a manipulation of the light level or the spectrum of white light, as was indicated by previous studies [19,26,41-43]. However, these earlier investigations did not explore the relative contribution of illuminance vs. spectral composition of polychromatic light, which are both vital characteristic determining the human NIF response to polychromatic light. Note that the correlated 
1 color temperature of polychromatic light would generally rise with increasing power in the blue part of

2 the spectrum. Thus, the current study aimed at systemically investigating the individual and combined

3 effects of illuminance level and spectral composition of polychromatic light on subjective alertness,

4 mood, and different cognitive domains during daytime working hours. Exploration of the individual and combined effects of illuminance and spectral composition on different cognitive domains may provide crucial insights into whether differentially manipulating office light level and correlated color

7 temperature (CCT) would be essential to optimize alertness, mood, and cognitive performance.

\subsection{The effects of light illuminance on cognition}

Reported diurnal effects of illumination on cognition are quite equivocal (see also [16,36]). Multiple studies revealed beneficial effects of illuminance on cognition, such as sustained attention [19,20,22], response inhibition [25], and working memory [26,27]. However, other studies found no statistically significant improvement of sustained attention performance [24,27,43-45] and working memory [28]. Besides that, a few investigations revealed that participants even performed worse while being exposed to a higher illuminance level in terms of impaired sustained attention, auditory response inhibition, and working memory, suggesting performance-undermining effects of illuminance on cognition $[19,26,46,47]$

\subsection{The effects of CCT on cognition}

It is widely accepted that the ipRGCs contain the photopigment melanopsin, and are primarily responsible for the non-image forming effects of light $[3,4,48]$. The ipRGCs differ from the classical rods and cones in their sensitivity to light characteristics $[1,4]$. Higher light levels, i.e., more photons, are necessary to induce melanopsin photoreception. In addition, the peak sensitivity of the photopigment melanopsin in ipRGCs to light is in the blue part of the spectrum (around 460 480 nm) $[1,4,49,50]$. The 
1 NIF effect of the spectral composition of light on human functioning has therefore also been partially

investigated, sometimes by comparing effects of monochromatic or small-bandwidth lighting, or by comparing white light that is or is not enhanced in the blue part of the spectrum. Note that the correlated color temperature (CCT) of polychromatic light generally increases when it contains more power in the blue part of the spectrum. It is expected that exposure to either monochromatic blue light or polychromatic light of high CCT would have stronger NIF effects [10,11,40,49-52]. However, the advantage of high CCT on cognition is not always confirmed during daytime [18] -- as was also the case for illuminance level [16,36]. Positive effects of CCT were found on sustained attention [53] and subjective measurement of performance [53,54]. For instance, $17000 \mathrm{~K}$ light improved subjective alertness and performance more strongly than $4000 \mathrm{~K}$ or $2900 \mathrm{~K}$ [54,55]. Yet, some studies showed no advantage of CCT level on sustained attention [18], alerting attention, orienting, and executive control [18], or working memory [29].

\subsection{Interactions of illuminance and correlated color temperature on cognition}

Most studies have tested effects of illuminance level at one specific CCT level, and vice versa.

Previous studies investigating the interaction effect of illuminance and correlated color temperature of polychromatic light are relatively scarce. It is, however, interesting to investigate this nonetheless in order to optimize daytime lighting regimes, as it may shed light on underlying mechanisms. In line with the most common hypothesis today, one might expect that the essence of both an illuminance and a CCT manipulation is their differential activation of melanopsin-driven photic transduction. Both may result in more intense ipRGC activity, and hence stronger NIF effects. But in fact, the extent to which the remaining photoreceptors contribute to these effects is still under investigation [56,57], and recent studies have suggested potential complex interactions (inhibition and facilitation) between activation of 
1 different photoreceptors [58,59]. If the activation of the traditional photoreceptors also adds to NIF

effects [60,61], one might perhaps expect CCT manipulations to show fewer effects on performance and alertness than illuminance manipulations. Also, we cannot discard the fact that the altered visual experience - through psychological, image forming pathways - may impact performance and alertness $[19,38]$. In that sense, CCT manipulations may result in equally strong, but perhaps different effects. In other words, based on melanopsin-driven NIF effects one would expect purely additive effects of a combined increase in CCT and illuminance, but if other receptors play a part via NIF or IF effects, interactions might also emerge. To date, there is uncertainty regarding the relative contribution of the different photoreceptors in NIF effects, but some contribution of non-melanopsin driven photoreceptors is often acknowledged, and this interaction may depend on the illuminance levels (e.g., see $[56,57,62,63])$.

Only a few studies investigated interaction effects between CCT and illuminance. One earlier study by Noguchi and Sakaguchi [64] reported that CCT (5000 vs. 3000 K) influenced physiological activity more than illuminance levels (150 vs. 50 lx) with higher values of EEG alpha attenuation coefficient and higher mean EEG frequency of the theta-beta ratio under $5000 \mathrm{~K}$ vs. $3000 \mathrm{~K}$ in the afternoon. Moreover, participants in $5000 \mathrm{~K}$ light subjectively reported less drowsiness than in $3000 \mathrm{~K}$ light, whereas no statistically significant effect of illuminance was observed [64]. In contrast, Min et al. [47] found that exposure to a higher illuminance (700 vs. $150 \mathrm{~lx}$ ) did decrease response speed on a sustained attention task, regardless of the CCT level (7100 vs. $3000 \mathrm{~K}$ ). Park and colleagues [28] also suggested that the NIF effect of polychromatic light on cognitive function may depend more strongly on illuminance than on CCT. They reported no statistically significant effects of illuminance level and CCT on behavioral performance of working memory task, but exposure to a higher illuminance (700 vs. 150 lx) delayed the 
1 onset latency of $\mathrm{N} 1$ and decreased the amplitude of theta component in frontal brain regions, again

regardless of CCT (7100 K vs. $3000 \mathrm{~K})$. The above studies testing effects of illuminance and CCT in one study paradigm have restricted their tests to a limited range of cognitive domains; it is still unclear whether the above findings would be evidenced in other cognitive functions as well. In addition, a recent study revealed enhanced mood and alertness, but impaired sustained attention with intense illumination at a relatively high CCT in the morning [46]. In their study, however, they failed to match the color temperature between the $5000 \mathrm{~lx}(6500 \mathrm{~K})$ and $400 \mathrm{~lx}(4000 \mathrm{~K})$ conditions appropriately. Due to this confound, it is impossible to attribute the effect to illuminance levels or CCT alone. Thus, the aim of the present study was to systemically explore the independent and combined effects of illuminance and CCT of polychromatic light on performance in a set of tasks probing various cognitive domains.

As was argued before, task type and task complexity may also be important moderators of light effects on cognition $[19,26,27,41,42]$. Hence, the current study employed a factorial design to manipulate illuminance and CCT independently and used a simple sustained attention task (psychomotor vigilance task; PVT), two more complex executive control tasks (Go/No-go and Flanker test), and a working memory task (paced visual serial addition task, PVSAT) to explore the contribution of illumination and CCT of polychromatic light across different cognitive domains during daytime. To achieve above aims, healthy adults were assigned to either high or low illuminance light (1000 lx vs. 100 lx at the eye) of either high or low CCT (6500 K vs. $3000 \mathrm{~K}$ ). In addition, the effect of illuminance and CCT on the development of participants' subjective mood and alertness, subjective appraisals, preference for a work-related context and beliefs of the light conditions were also investigated.

\section{Methods}




\subsection{Design}

The study employed a 2 within (Illuminance level: 1000 lx vs.100 lx) by 2 between (CCT: $6500 \mathrm{~K}$ vs. $3000 \mathrm{~K}$ mixed model design. Participants came to the lab on two separate days with an interval of at least three days in between experimental sessions. The study was carried out during daytime hours (10:00 17:00) and participants were scheduled at the same local clock time for both experiment days.

\subsection{Participants}

Fifty-seven healthy undergraduates (38 females, $M=20.23$; $\mathrm{SD}=1.58$ ) participated in the laboratory study. Twenty-eight participants (19 females) were randomly assigned to the low CCT (3000 K) condition, while the others (19 females) were assigned to the high CCT $(6500 \mathrm{~K})$ condition. Participants were randomly assigned to receive either 1000 lx light exposure or 100 lx light exposure first.

All volunteers were screened and reported no visual impairments other than myopia or hyperopia, which were corrected by wearing contact lenses or glasses, and none of them indicated that they suffered from color blindness. Potential candidates were screened for physical and mental health problems, according to their self-reports and responses on the General Medical Questionnaire [65]. Other exclusion criteria included (1) smoking, medication or drug consumption, (2) recent travel to a different time zone or shift-work in the last three months, (3) less than 7 hours or more than 9 hours spent in bed at night, (4) Pittsburgh Sleep Quality Index score > 5 [66], and (5) extremely late or extremely early chronotype on the Munich Chronotype questionnaire (MCTQ) [67].

All participants gave their written informed consent before the start of the study, and followed the complete experimental protocol.

\subsection{Setting and light manipulation}


The lab room (Fig.1) where the experiment was conducted was a simulated office environment of

2

3

4

$3.6 \mathrm{~m}$ by $3.6 \mathrm{~m}$. Four separate workstations with a pure white desk $(1.2 \mathrm{~m}$ by $0.8 \mathrm{~m})$ and one black chair were created. One white All-in-One PC (Lenovo C260, 19.5 inch) with the white headphone, keyboard and mouse was placed on each of the desks.

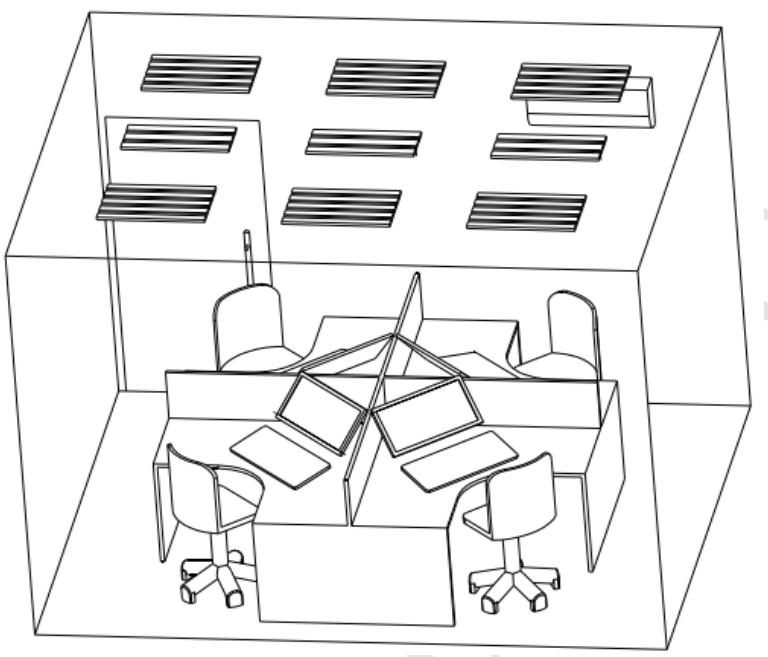

Fig. 1. Simulated office room where the ambient light parameters were manipulated and other physical variables were controlled.

The room was equipped with six ceiling mounted luminaires of $1.2 \mathrm{~m}$ by $0.8 \mathrm{~m}$ containing three Philips LED tubes (either T8-28W/865 or T8-28W/830) and three additional ceiling mounted luminaires of $1.2 \mathrm{~m}$ by $0.6 \mathrm{~m}$ containing two Philips LED tubes (T8-28W). Using a calibrated spectroradiometer (JETI Specbos1201), the illuminance level, spectral power distribution (SPD) and color-rendering index (CRI) were measured at eye level aimed at the wall in the gaze direction of participants. The CRI at $6500 \mathrm{~K}$ was $\mathrm{Ra}=81$, and the CRI at $3000 \mathrm{~K}$ was $\mathrm{Ra}=83$. Fig. 2 shows the $\mathrm{SPD}$ at $6500 \mathrm{~K}$ and $3000 \mathrm{~K}$ of the $1000 \mathrm{~lx}$ and $100 \mathrm{~lx}$ conditions. 


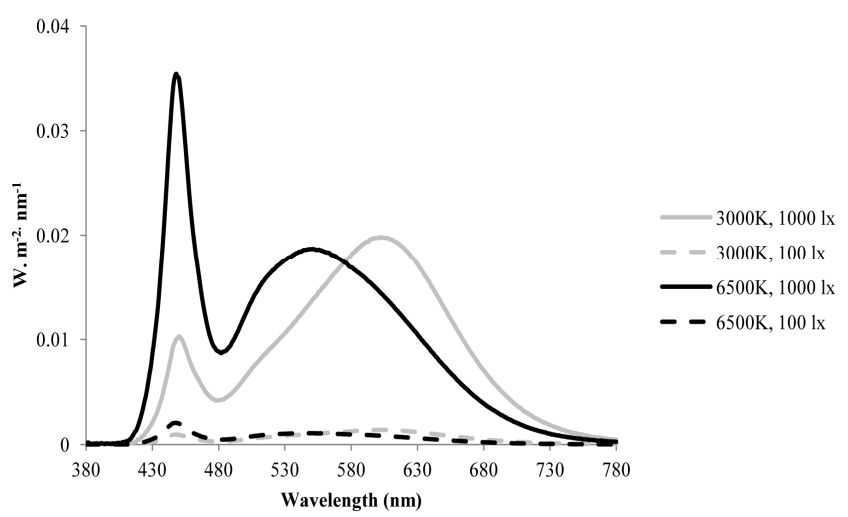

Fig. 2. Spectral power distribution measured at eye level in the four lighting conditions. level (photon density: $9.07 \times 10^{13}$ photons $\mathrm{s}^{-1} * \mathrm{~cm}^{-2}$; irradiance: $31 \mu \mathrm{W} / \mathrm{cm}^{2} ; 118 \mathrm{~lx}$ on the table surface), to $1000 \mathrm{~lx}$ at $3000 \mathrm{~K}$ at eye level (photon density: $9.54 \times 10^{14}$ photons $^{*} \mathrm{~s}^{-1} * \mathrm{~cm}^{-2}$; irradiance: $324 \mu \mathrm{W} / \mathrm{cm}^{2 \text {; }}$ $1620 \mathrm{~lx}$ on the table surface), to $100 \mathrm{~lx}$ at $6500 \mathrm{~K}$ at eye level (photon density: $8.99 \times 10^{13}$ photons* $\mathrm{s}^{-1} * \mathrm{~cm}^{-2}$; irradiance: $33 \mu \mathrm{W} / \mathrm{cm}^{2} ; 116 \mathrm{~lx}$ on the table surface), or to $1000 \mathrm{~lx}$ at $6500 \mathrm{~K}$ at eye level (photon density: $9.28 \times 10^{14}$ photons $* \mathrm{~s}^{-1} * \mathrm{~cm}^{-2}$; irradiance: $341 \mu \mathrm{W} / \mathrm{cm}^{2} ; 21901 \mathrm{x}$ on the table surface). See Table 1 for additional information about the lighting conditions based on the spectral sensitivity of the various photoreceptors.

Table 1.

Spectrally-weighted $\alpha$-Opic lux level at eye levels for each lighting condition based on calculations of Lucas et al. (2014) [56].

\begin{tabular}{lccccc}
\hline & & \multicolumn{4}{c}{$\alpha$-Opic lux value } \\
\cline { 3 - 6 } & $\lambda$ max & $(3000 \mathrm{~K}, 100 \mathrm{~lx})$ & $(3000 \mathrm{~K}, 1000 \mathrm{~lx})$ & $(6500 \mathrm{~K}, 100 \mathrm{kx})$ & $(6500 \mathrm{~K}, 1000 \mathrm{kx})$ \\
\hline Lux & 99 & 1037 & 102 & 1040 \\
CCT & 3069 & 3088 & 6589 & 6666 \\
Melanopsin & 480 & 56 & 534 & 96 & 998 \\
S-cone & 419 & 47 & 385 & 105 & 1081 \\
M-scone & 530 & 85 & 872 & 102 & 1044 \\
L-cone & 558 & 97 & 1022 & 99 & 1003 \\
Rods & 496 & 66 & 643 & 98 & 1026
\end{tabular}


non-visual responses are initiated by one or more of five distinct biological representations of irradiance: melanopic, rhodopic, cyanopic, chloropic, and erythropic illuminance.

\subsection{Assessment of subjective ratings}

Subjective alertness was assessed with the Karolinska Sleepiness Scale (KSS) [68], while the Positive and Negative Affect Scale (PANAS) [69] was used to assess subjective mood.

\subsection{Cognitive performance measurement}

Four tasks were employed to assess the light's effect on different aspects of cognitive functioning.

Simple sustained attention was measured by the psychomotor vigilance task [70]. We used a 10-minute auditory PVT, with intervals randomly varying from 1 to 9 s. A visual Go/No-go task measured the capacity for sustained attention and response inhibitory [11,71]. In this test, participants had to press the key button within 1 second if the letter "M" was shown on the screen, and withhold response to the letter "W". The interval between trials was varying from 1 s to $1.5 \mathrm{~s}$, and a total of $70 \%$ of " $\mathrm{M}$ " letters were shown in a random sequence. The letters " $\mathrm{M}$ " and "W" were printed in black and with size of 30pt on purely white screen. The Eriksen flanker task is an executive function test used to assess selective attention and inhibition of conflicting irrelevant information [72]. In the task, a directional response was made to a central target stimulus by striking the left or right arrow on the computer keyboard. The target was randomly flanked by non-target stimuli, which corresponded either with the same (congruent flankers) or the opposite (incongruent flankers) directional response as the target. All 50 stimuli were black-and-white pictures that had been processed through Photoshop and the size of the picture was $500 * 375$ pixels. The average accuracy and reaction times for both the congruent and incongruent presentations were separately recorded for the analyses. PVSAT is an addition task that engages with the executive aspect of working memory [73]. Single digits (1 to 20) colored in black (30pt) appear on the white screen and each digit must be added to the digit that preceded it. The resulting answer ("sum" of 
1 adjacent pairs, not a total across all digits presented) is keyed in with the numerical keyboard. Digits were

2 presented for $1 \mathrm{~s}$, and then responses were allowed within a $5 \mathrm{~s}$ maximum, followed by a 1 -s interval

3 before the next stimulus appeared.

4

\subsection{Evaluation of the lighting}

At the end of the session, participants were asked to evaluate the lighting environment in the lab using six 5-point Likert-scale items adopted from Flynn et al. [74], including appraisals of the lighting in terms of brightness (dim - bright), color temperature (warm - cool), pleasant (unpleasant - pleasant), comfortable (uncomfortable - comfortable), disturbing (not distributed-distributed), and soft (not soft soft). In addition, three 9-point Likert-scale items on participants' subjective beliefs of the current lighting effects on energy, mood, and work performance (i.e. whether the lighting benefited your performance, "1" does not benefit, "9" benefit) were administered as well as one item to probe participants' preference to work under the current lighting in daily life was evaluated on a 7-point scale ranging from (1) extremely inadequate to (7) extremely adequate.

\subsection{Procedure}

All potential participants were required to fill in online questionnaires, including questions about demographics, physical and mental health, general sleep quality and chronotype after their registration. Participants were instructed to comply with their regular night sleep schedule $( \pm 30 \mathrm{~min}$ as they reported in the MCTQ) for at least one week before the laboratory study and kept it until they completed all the experiments, and to abstain from drinking beverages containing alcohol or caffeine on both the experiment days. 


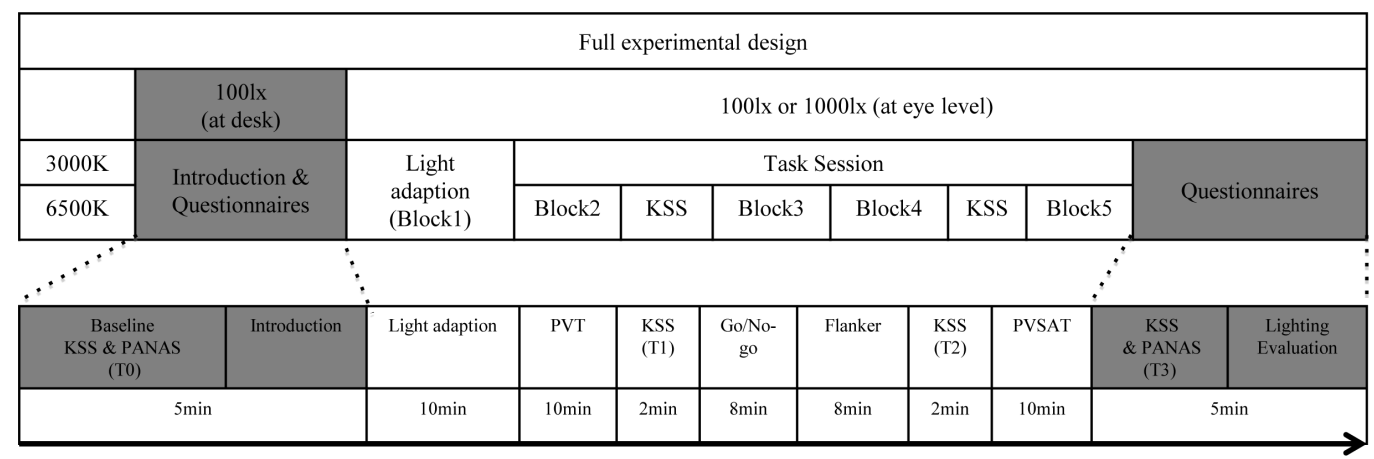

Fig. 3. Overview experimental condition and schematic representation of one full session. PVT: Psychomotor Vigilance test; KSS: Karolinska Sleepiness Scale; PANAS: Positive and Negative Affect Scale. Tasks were run in two orders (PVT-PVSAT-Flanker-Go/No-go or PVT- Go/No-go -Flanker- PVSAT)

After arriving in the laboratory, participants were asked to complete a brief interview including questions on their sleep-wake timing and sleep quality that day, whether they drank beverages containing alcohol or caffeine, or had vigorous excise or long-term (more than $2 \mathrm{~h}$ ) outdoor activities before arriving in the lab. Participants who reported bad sleep quality or did not adhere to the sleep-wake schedule during the night preceding an experimental session, and/or those participants who did not adhere to the other instructions (e.g., drank alcoholic beverages) were rescheduled to another day.

Subsequently, participants were guided to the workstation and asked to assess their baseline sleepiness and mood with questionnaires. After that, participants were informed about the general procedure and started the formal experimental phase. The experiment started always with a 10-minute light adaption (Block 1) and then four computerized task blocks (Blocks 2, 3, 4, and 5: PVT, Go/No-go, Flanker and PVSAT task respectively) programmed with one of the two fixed task orders (either PVTGo/No-go - Flanker - PVSAT or PVT - PVSAT - Flanker - Go/No-go). The task order was identical for each participant on two experiment days. Participants reported on their current alertness and mood at baseline (T0), twice during the test session (at $\mathrm{T} 1$ and $\mathrm{T} 2$ ) and once more at the end of the test session (T3). At T3, participants also completed the mood questionnaire and a questionnaire evaluating the 
1 lighting environment in the laboratory. A schematic representation of one full experimental session is

2 depicted in Fig. 3.

\subsection{Data analysis}

The scores of the positive subscale and the negative subscale of the PANAS were averaged for each participant respectively. Reaction times (RT) on error trials (omissions, false starts and trials following incorrect responses) and outliers (more than three standard deviations from the mean) were removed per participant for the various performance tasks before calculating the averages. All RT data were inverted before further analysis to increase normality. For the PVT data, the average reaction speed (1/RT) for overall trials, the average speed for the $10 \%$ fastest and the $10 \%$ slowest responses were separately investigated. Lapses in the PVT task were not investigated since the number of lapses was quite low and not normally distributed.

For all analyses, SPSS version 19.0 (IBM, USA) was used. In order to test whether the baseline alertness and mood were different across four experiment conditions, two-way repeated measures ANOVAs with within-subject factor Illuminance (1000 lx vs. 100 lx) and between-subject factor CCT (6500 K vs. $3000 \mathrm{~K}$ ) were performed for baseline alertness and mood. Since subjective sleepiness was assessed multiple times, Testing time (T1, T2 vs. T3) was added as a within-subjects factor in the analysis of effects of light on changes $(\triangle)$ of subjective alertness. Two-way repeated measures ANOVAs with within-subject factor Illuminance and between-subject factor CCT were also performed to test the effect of the lighting conditions on subjective mood and appraisals of lighting. For task performance, two-way repeated measures ANOVAs with within-subject factor Illuminance and between-subject factor CCT were performed. Congruency (congruent/incongruent) was added as an additional within-subject factor in the repeated-measures ANOVAs for accuracy and reaction speed in the Flanker task. Note that 
1 reported contrasts for main effects and interaction effects always refer to post-hoc analyses using

Bonferroni correction.

\section{Results}

\subsection{Subjective measurement}

3.1.1 Baseline comparisons

Repeated measures ANOVAs with the factors Illuminance (within: 1000 lx vs. 100 lx) and CCT

(between: $6500 \mathrm{~K}$ vs. $3000 \mathrm{~K}$ ) was performed first on baseline data for alertness and mood. The results indicated that - at baseline (T0) - there were no significant main or interaction effects of illuminance and CCT conditions on subjective alertness $[100 \mathrm{~lx}$ at $6500 \mathrm{~K}: M=3.34 \pm S E=.24 ; 1000 \mathrm{~lx}$ at $6500 \mathrm{~K}$ : $3.31 \pm .20 ; 100 \mathrm{~lx}$ at $3000 \mathrm{~K}: 3.39 \pm .25 ; 1000 \mathrm{~lx}$ at $3000 \mathrm{~K}: 3.32 \pm .26]$, positive $\operatorname{mood}[100 \mathrm{~lx}$ at $6500 \mathrm{~K}$ : $2.00 \pm .11 ; 1000 \mathrm{~lx}$ at $6500 \mathrm{~K}: 1.80 \pm .12 ; 100 \mathrm{~lx}$ at $3000 \mathrm{~K}: 1.77 \pm .11 ; 1000 \mathrm{~lx}$ at $6500 \mathrm{~K}: 1.74 \pm .13]$ or negative mood [100 lx at $6500 \mathrm{~K}: 1.21 \pm .05 ; 1000 \mathrm{~lx}$ at $6500 \mathrm{~K}: 1.20 \pm .06 ; 100 \mathrm{~lx}$ at $3000 \mathrm{~K}: 1.42 \pm .06$; $1000 \mathrm{~lx}$ at $3000 \mathrm{~K}: 1.42 \pm .05]$ (all $p$ values > .05).

3.1.2. Effects of lighting manipulations on subjective alertness

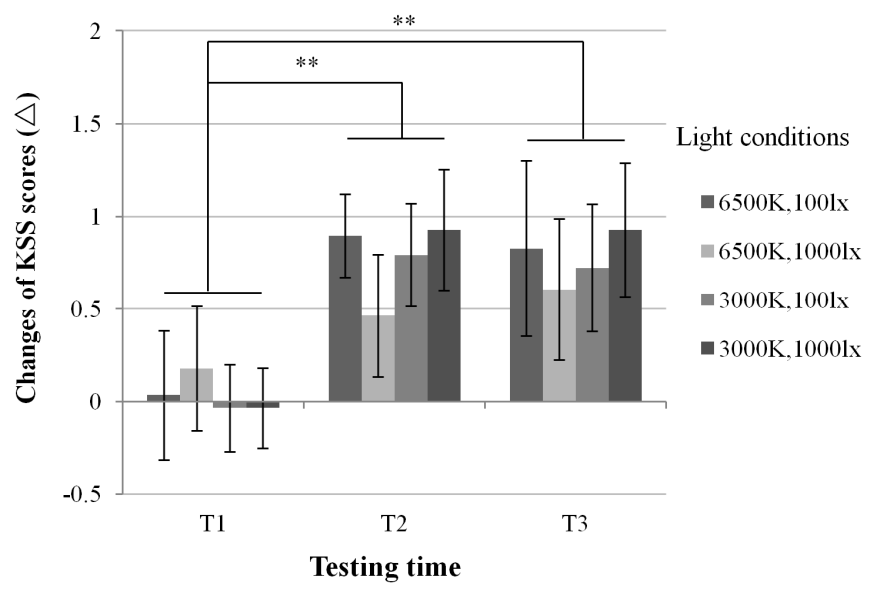

Fig. 4. The changes in KSS score relative to baseline for different light conditions during the experimental session. Error bars indicate \pm 1 standard error of the mean. $* * p<.01$. 
The development of the average change in KSS score relative to T0 ( $\triangle$ KSS) during the lighting

(
session is shown in Fig. 4. A repeated ANOVA with within factors Illuminance level and Test time, and between factor CCT on $\triangle \mathrm{KSS}$ showed a significant main effect of Test time $\left[F(2,110)=9.81, p<.01, \eta^{2}\right.$ $=.15]$. Post-hoc comparisons showed that the increase in KSS score (i.e., lower alertness compared to baseline) was significantly larger at Time2 and Time3 than that at Time1 [all $p<.01]$, no statistically significant differences emerged between Time 2 and Time $3[p>.05]$. The lighting conditions revealed no significant main or interactions effects (all $p$ values $>.05$ ).

\subsubsection{Mood}

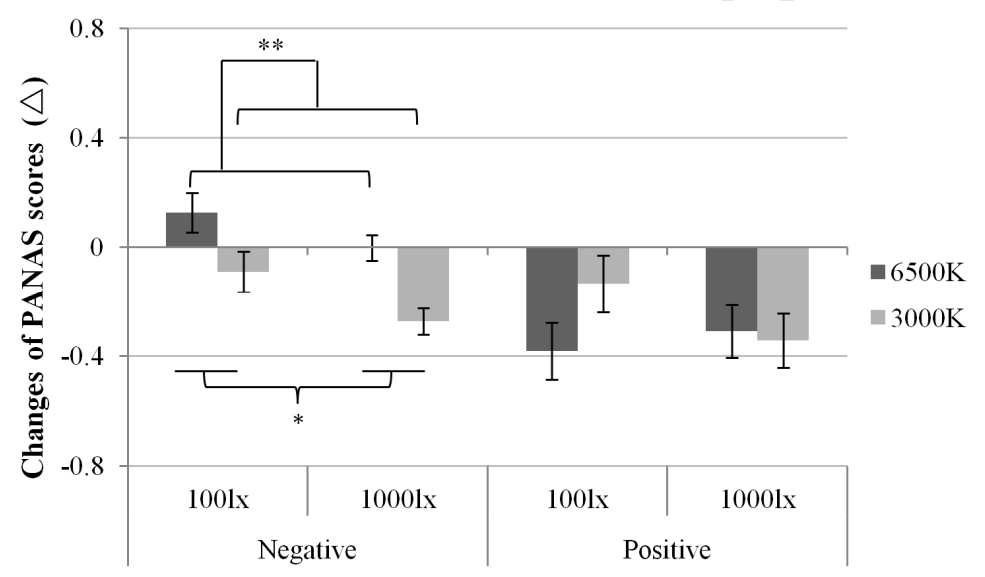

Fig. 5. Changes in PANAS scores (negative and positive affect) relative to baseline for different light conditions over the experimental session. Delta negative means PANAS scores decreased and vise versa. Error bars indicate \pm 1 standard error of the mean.* $p<.05 . * * p<.01$.

\section{The average changes in PANAS scores during the test session are show in Fig. 5. A repeated}

measures ANOVA with the factors Illuminance and CCT on the changes in subjective mood revealed that participants' negative mood decreased more in the 1000 lx vs. $1001 x$ condition $[-0.14 \pm .03$ vs. $0.02 \pm .05$, $\left.F(1,55)=6.10, p<.05, \eta^{2}=.10\right]$, as well as in the $3000 \mathrm{~K}$ vs. $6500 \mathrm{~K}$ condition $[-0.18 \pm .04$ vs. 0.06 $\left.\pm .04, F(1,55)=16.32, p<.01, \eta^{2}=.22\right]$. No significant Illuminance $\times$ CCT interaction was found $[F(1$, $55)=.32 ; F(1,55)=.17 ;$ all $\left.p>.05, \eta^{2}<.01\right]$. In contrast, the repeated measures ANOVA for positive affect did not reveal any significant effects on the changes in subjective positive mood [main effect 
1 Illuminance: $F(1,55)=.53$; main effect CCT: $F(1,55)=.98$; interaction effect: $F(1,55)=2.26$; all

$\left.2 p>.05, \eta^{2}=.1\right]$.

$3 \quad 3.2$ Task performance measurement

$4 \quad$ 3.2.1 Effects of lighting manipulations on sustained attention

5
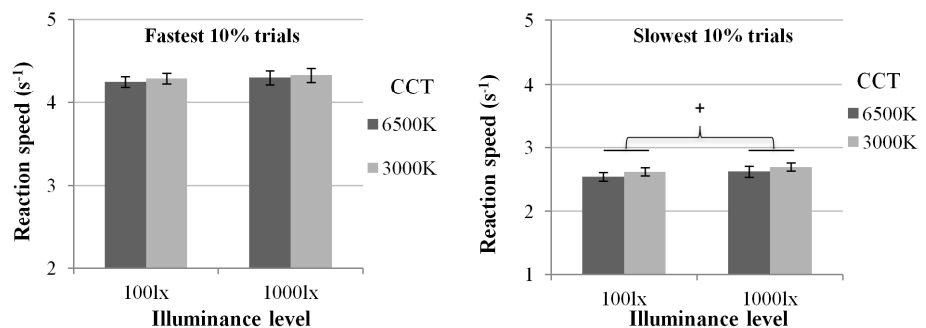

Fig. 6. PVT performance of speed on overall trials (left panel) and $10 \%$ fastest trials (middle panel) and $10 \%$ slowest trials (right panel) in 100 lx vs. 1000 lx at $6500 \mathrm{~K}$ (dark bars) vs. $3000 \mathrm{~K}$ (light bars) condition. Error bars indicate \pm 1 standard error of the mean. $+p=.05$.

A repeated-measures ANOVA computed on PVT performance (speed) revealed no significant main effects of Illuminance or CCT on overall reaction speed $\left[F(1,55)=3.21, p=.08, \eta^{2}=.06 ; F(1,55)=.77\right.$, $p>.05, \eta^{2}=.01$, respectively]. The average speed on the $10 \%$ fastest trials also revealed no significant effects of Illuminance or CCT $\left[F(1,55)=.91, p>.05 \eta^{2}=.02 ; F(1,55)=.13, p>.05, \eta^{2}<.01\right.$, respectively], while the main effect of Illuminance (not CCT) on the $10 \%$ slowest trials bordered on significance [Illuminance: $F(1,55)=3.98, p=.05, \eta^{2}=.07$; CCT: $\left.F(1,55)=.65, p>.05, \eta^{2}=.01\right]$. In addition, no significant Illuminance $\times$ CCT interaction effects were found for PVT performance [all $F$ $<1, n s, \eta^{2}<.01$ ] (see Fig. 6). 3.2.2. Effects of lighting manipulations on response inhibition (Go/No-go) Results on the Go/No-go accuracy (Figure 6) revealed no significant effect of Illuminance or CCT $\left[F(1,55)=2.65, p>.05, \eta^{2}=.05 ; F<1, n s, \eta^{2}<.01\right.$, respectively $]$, or of their interaction $[F(1,55)=2.42$, $\left.p>.05, \eta^{2}=.04\right]$. However, the main effect of Illuminance on reaction speed in this task did reach significance. Reaction speed was higher in the $1000 \mathrm{~lx}$ vs. $100 \mathrm{~lx}$ condition [2.62 \pm .03 vs. $2.56 \pm .02, F(1$, 
$\left.155)=6.13, p=.02, \eta^{2}=.10\right]$. The main effect of CCT and the Illuminance $\mathrm{x}$ CCT interaction effect did not reach significance $\left[F(1,55)=1.14, p>.05, \eta^{2}=.02 ; F<1, n s, \eta^{2}<.01\right.$, respectively] (see Fig. 7).
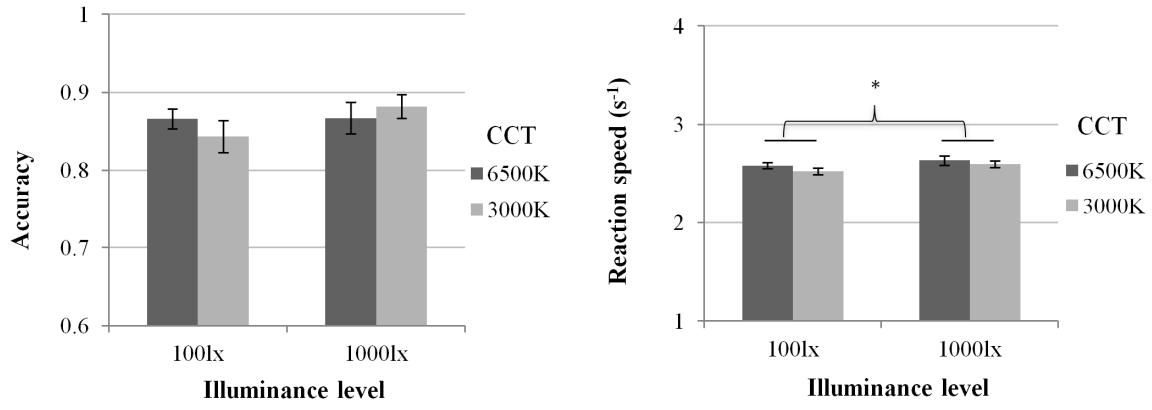

Fig. 7. Go/No-go accuracy (left panel) and reaction times (right panel) in $100 \mathrm{~lx}$ vs. $1000 \mathrm{~lx}$ at $6500 \mathrm{~K}$ (dark bars) vs. $3000 \mathrm{~K}$ (light bars). Error bars indicate \pm 1 standard error of the mean. $* p<.05$.

3.2.3. Effects of lighting manipulations on conflict monitoring (Flanker)
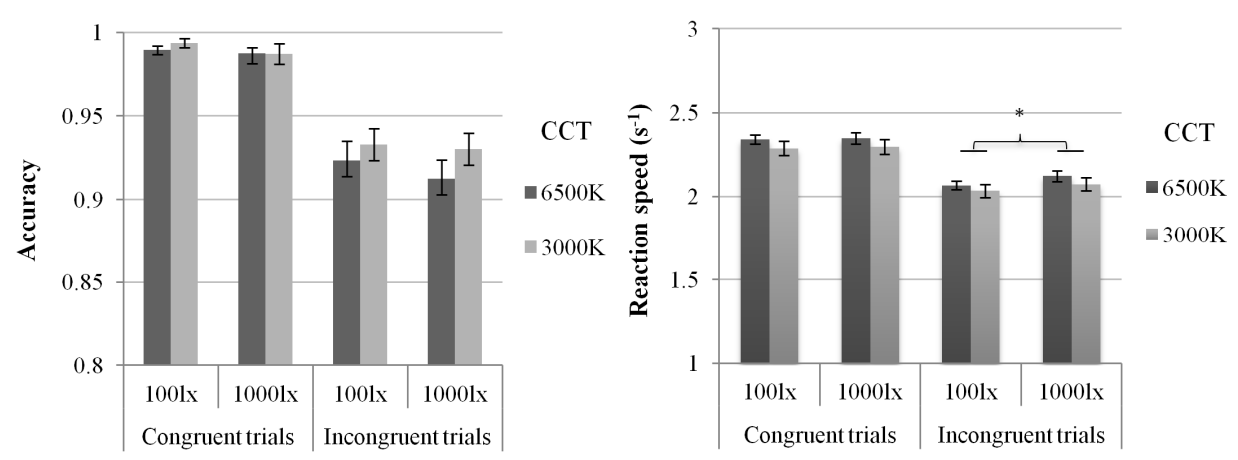

Fig. 8. Flanker accuracy (left panel) and reaction times (right panel) in 100 lx vs. 1000 lx at $6500 \mathrm{~K}$ (dark bars) vs. $3000 \mathrm{~K}$ (light bars) condition. Error bars indicate \pm 1 standard error of the mean. $* p<.05$.

A three-way repeated measures ANOVA on Flanker accuracy revealed no significant main effects of Illuminance or CCT (Fig. 8) $\left[F(1,55)=2.24, p>.05, \eta^{2}=.04 ; F<1, n s, \eta^{2}=.02\right.$, respectively] (see Fig. 8). The main effect of Congruency was significant: participants performed better for the congruent vs. incongruent trials $\left[.99 \pm .002\right.$ vs. $\left..93 \pm .007, F(1,55)=118.88, p<.01, \eta^{2}=.68\right]$. No significant interactions were found for Flanker accuracy (all $p$ values > .05).

The average reaction speed (Fig. 8b) also disclosed a significant main effect of Congruency, with reaction speed significantly higher for the congruent vs. incongruent trials [2.30 \pm 0.02 vs. $2.06 \pm .02, F(1$, 
$\left.155)=964.52, p<.01, \eta^{2}=.95\right]$. Main effects of Illuminance and CCT did not reach significance $[F(1,55)$

$2=2.30, p>.05, \eta^{2}=.04 ; F<1, n s, \eta^{2}=.02$, respectively]. However, the interaction between Illuminance

3 and Congruency did reach significance $\left[F(1,55)=15.61, p<.01, \eta^{2}=.22\right]$. The post-hoc tests revealed

4 that participants' reaction speed for the incongruent Flanker trials was significantly higher under $1000 \mathrm{~lx}$

5 vs. 100 lx condition $[2.10 \pm .03$. vs. $2.05 \pm .02, p<.05]$, while reaction speed for the congruent Flanker

6 trials did not significantly differ between $1000 \mathrm{~lx}$ vs. $100 \mathrm{~lx}$ conditions [2.31 \pm .03 . vs. $2.32 \pm .03, p>.05$ ].

$7 \quad$ No other interactions reached significance (all $p$ values $>.05$ ).

8 3.2.4. Effects of lighting manipulations on working memory (PVSAT)
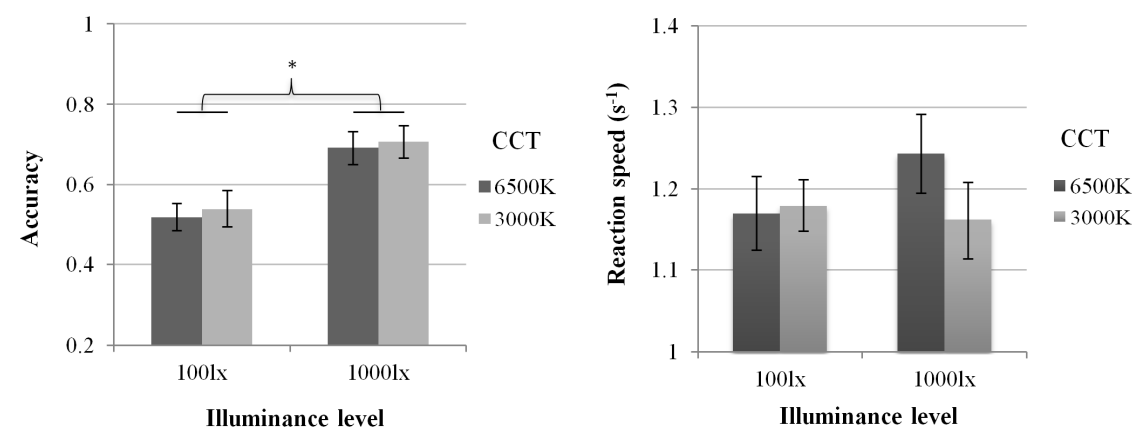

9

10

11

Fig. 9. PVSAT accuracy (left panel) and reaction times (right panel) in $100 \mathrm{~lx}$ vs. $1000 \mathrm{~lx}$ at $6500 \mathrm{~K}$ (dark bars) vs. $3000 \mathrm{~K}$ condition (light bars). Error bars indicate \pm 1 standard error of the mean. $* p<.05$.

Result for accuracy in the PVSAT task (Fig. 9) revealed a significant main effect of Illuminance.

Participants' accuracy was average higher in the 1000 lx vs. 100 lx condition $[0.70 \pm .04$ vs. $0.53 \pm .03$, $\left.F(1,55)=84.79, p<.01, \eta^{2}=.61\right]$. The main effect of CCT and the Illuminance $\times$ CCT interaction did not reach significance [both $F<1, n s, \eta^{2}<.01$ ]. The reaction speed in PVSAT task, however, did not reveal any significant main effects nor interaction effect [main effects Illuminance and CCT: $F<1, n s, \eta^{2}$ $<.01$; Interaction: $\left.F(1,55)=2.65, p>.05 ; \eta^{2}=.05\right]$.

\subsection{Evaluation of lighting}




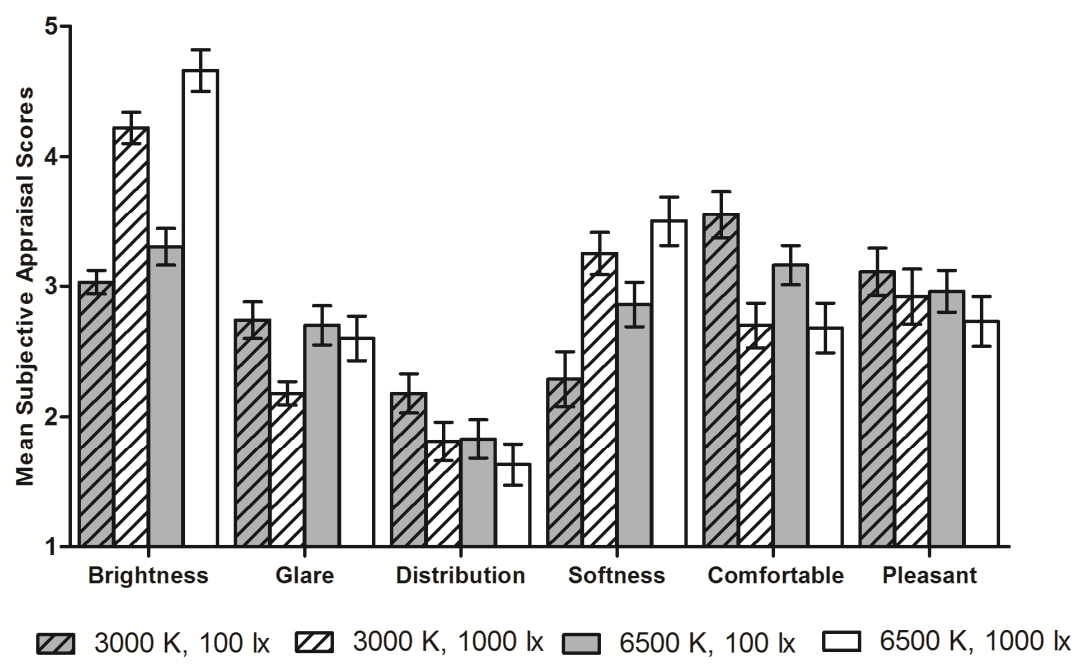

Fig. 10. Mean score on subjective appraisals of lighting in different experimental conditions

Repeated-measures ANOVA analyses with Illuminance (within) and CCT (between) were performed to examine effect on participants' subjective appraisals, beliefs and preference of the lighting conditions. The results for the lighting appraisals (see Fig. 10) revealed that the 1000 lx light was perceived as brighter $\left(4.44 \pm .10\right.$ vs. $\left.3.17 \pm .09, F(1,55)=113.00, p<.01, \eta^{2}=.67\right)$, but less soft $(2.38 \pm .13$ vs. 2.58 $\left.\pm .14, F(1,55)=14.03, p<.01, \eta^{2}=.20\right)$ and less comfortable $(2.68 \pm .13$ vs. $3.36 \pm .12, F(1,55)=11.18$, $\left.p<.01, \eta^{2}=.18\right)$ than the $100 \mathrm{~lx}$ light. Meanwhile, light in the $6500 \mathrm{~K}$ condition was evaluated as softer $\left(3.18 \pm .11\right.$ vs. $\left.2.77 \pm .11, F(1,55)=6.62, p<.05, \eta^{2}=.11\right)$ and brighter $(3.98 \pm .13$ vs. $3.62 \pm .08, F(1,55)$ $=5.42, p<.05, \eta^{2}=.09$ ) than light of $3000 \mathrm{~K}$. In addition, the results (see Fig. 11) showed that light of $1000 \mathrm{~lx}$ was judged as more beneficial for task performance than that of $100 \mathrm{~lx}(6.67 \pm .16$ vs. $5.70 \pm .14$, $\left.F(1,60)=22.58, p<.01, \eta^{2}=.29\right)$, however, lighting of $3000 \mathrm{~K}$ was believed to benefit subjective mood more than that of $6500 \mathrm{~K}\left(5.44 \pm .18\right.$ vs. $\left.4.75 \pm .14, F(1,55)=9.53, p<.01, \eta^{2}=.15\right)$ than that of $6500 \mathrm{~K}$. No significant interaction between illuminance level and CCT were found on subjective appraisals, beliefs and preference. 


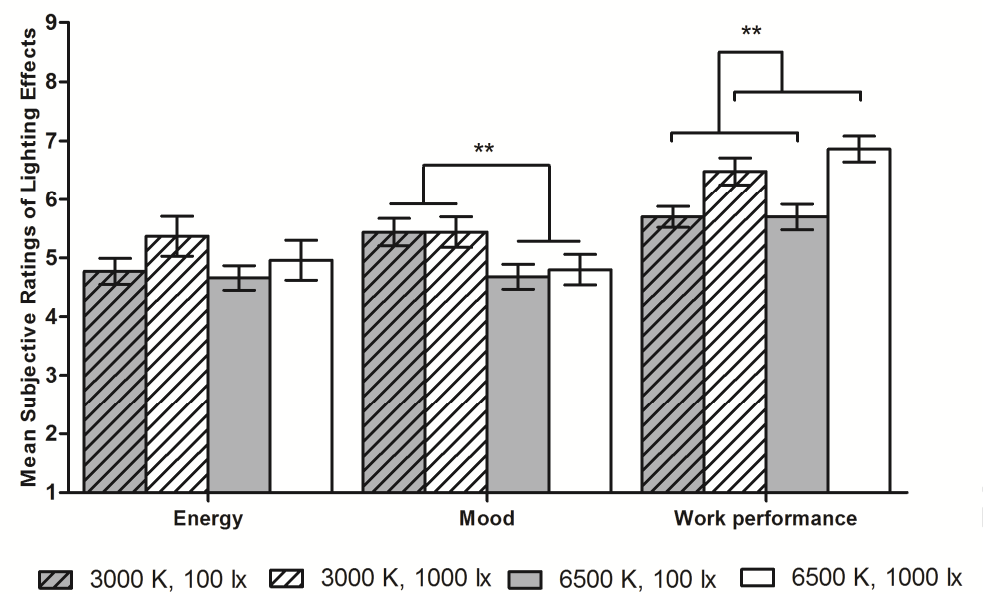

\section{Discussion}

Previous studies have investigated and reported acute effects of illuminance and CCT of light on alertness, task performance, and physiological arousal during daytime. These investigations, however, did not draw a conclusive finding. Moreover, the relative contribution of illuminance and CCT on various cognitive domains was largely unknown. Thus, the current study was conducted in an effort to provide a more comprehensive picture of the potential diurnal effects of office lighting on subjective alertness, mood, and different cognitive domains, by studying both dimensions in parallel and through separating and comparing the relative contribution of illuminance and spectrum of polychromatic white light.

Overall, the current results revealed that the illuminance level of office lighting influenced individuals' subjective measures and cognitive process more than CCT level. Statistically significant interaction effects between illuminance and CCT did not emerge on any of the indicators for subjective experiences or performance. Manipulations of illuminance did impact several performance measures and mood, though not subjective alertness. Only subjective mood and appraisals of the lighting were 
responsive to the CCT manipulation in the current study.

Although the current results revealed several benefits of illuminance level on task performance, the manipulation of spectrum (via CCT level) did not produce any significant performance improvements. In other words, our study did not render the advantage of light with high CCT reported in earlier studies $[11,54,55]$. Two possible factors may explain the absence of advantage of a higher CCT level in the current study. First, the melanopsin-expressing ipRGCs, which are primarily responsible for the NIF effect, were less affected by the manipulation of CCT level than illuminance level. It is widely documented that the ipRGCs differ from the classical photoreceptors (rods and cones) in their response to light characteristics [1,4] particularly with regard to peak sensitivity (around 460 480 nm) [4,49,50]. With the manipulation of the lighting conditions in the current study, the melanopic alpha-opic lux level increased quite modestly between CCT conditions (56 vs. 96 at 100 lx at eye level; 534 vs. 998 at 1000 lx at eye level). In other words, it increased with almost a factor two, whereas the illuminance manipulation implied a tenfold increase (melanopic lux at eye level: 56 vs. 534 at $3000 \mathrm{~K} ; 96$ vs. 998 at $6500 \mathrm{~K}$ ). Meanwhile, earlier field studies that reported activating effects of daytime exposure under high CCT on participants' subjective performance, employed either longer exposure durations (i.e., several weeks) and/or extremely high CCT levels (i.e., $17000 \mathrm{~K}$ vs. $4000 \mathrm{~K}$ ) [53-55]. Together, these findings suggest that an even higher CCT level and/or a longer exposure duration could be essential to induce alertness-enhancing effects. Additional studies are required to examine whether exposure to extremely higher CCT level (e.g., $17000 \mathrm{~K}$ ) for short duration (i.e., 30-minutes or 1 hour) or to relatively high CCT (i.e., $6500 \mathrm{~K}$ ) level for long duration (i.e., 2 hours or 3 hours) could induce alertness-enhancing effects during biological daytime. Moreover, additional research is required to establish thresholds for the alerting potential of melanopic activation in terms of alertness and cognitive performance. 
Second, the illuminance levels were tested as a within-subject factor in the current study, while

between-subjects manipulation was employed for CCT level. This may result in a potential (larger)

influence of inter-individual differences in the dependent measures between CCT conditions. Although participants' baseline mental state (i.e., alertness, affect), chronotype, and total sleep duration of the preceding night were not significantly different across lighting conditions, we did not measure participants' performance ability at baseline, or other sleep parameters (i.e., onset, offset and also midsleep) across the lighting conditions. Moreover, participants were potentially not blind to the manipulation of illuminance level, but did not experience the CCT manipulation due to the mixed design. In addition, the statistical power was higher for Illuminance than CCT due to the repeated measures across the 1000 lx and 100 lx conditions within subjects

While task performance remained insensitive to the CCT level, the illuminance manipulation induced both positive and null effects on task performance. Various types of tasks were adopted in the current study to explore the individual or combined effect of daytime exposure to bright vs. dim white light and high vs. low CCT on different components of cognition. For the PVT task, measuring sustained attention, only subtle improvements of reaction speed for the $10 \%$ slowest trials emerged under high vs. low illuminance condition. For the other tasks probing more complex cognitive functions, the current results, however, suggested statistically significant benefits of exposure to bright light, although not on all indicators of every task. Working memory as assessed with the PVSAT improved in terms of accuracy, whereas response inhibition, assessed with the Go/No-Go task, and conflict monitoring, assessed with the Flanker task, improved in terms of response speed. It is notable that the current benefits of illuminance level emerged under both bright light at $6500 \mathrm{~K}$ and bright light at $3000 \mathrm{~K}$. Moreover, the effect sizes for the significant effects of illuminance on Go/No-Go task and PVSAT performance ranged 
1 from medium to large. Yet, additional research studying the effects of light on performance in situ is needed to establish the practical relevance of the obtained results.

The current finding on sustained attention did not confirm the expectation that, during daytime, performance on the relatively simple attention task would be significantly improved with high vs. low light levels [20,22]. Differences in study protocol may partly explain these contradictory findings, since participants were sleep deprived in the study by Phipps-Nelson et al. [22] studies. In contrast, participants who were not sleep-restricted in in the study by Smolders et al. [20] study showed faster responses on the PVT under 1000 lx vs. 200 lx (at the eye) condition during regular working hours. However, this effect was only observed in the morning session, but not in the afternoon. In contrast, several studies also suggested no statistical significant effects of Illuminance or CCT level on vigilance (PVT) performance among healthy day activity participants during daytime [18,26,27,44-46]. It is notable that the non-significant improvement of sustained attention performance in the current study may also be traced back to the fact that the PVT task was always performed first during each session. In fact, Smolders et al. (2012) [20] and Smolders and de Kort (2014) [19] showed most pronounced effects of bright light on PVT response times after about 30 minutes of exposure. Regarding the effects on more complex cognitive tasks (i.e., executive functions), previous research reported inconsistent effects, including positive, null or even negative effects of daytime exposure to high illuminance level on Go/No-go tasks $[19,42]$, as well as on working memory tasks $[19,26,27,41,42]$. The current results revealed that the illuminance manipulation during daytime elicited selective benefits on performance for executive control (speed) and working memory (accuracy). It is difficult to directly compare the findings from previous studies and the current one, due to differences in lighting properties and experimental paradigms across these studies. Besides, the task characteristics (i.e type of task or task difficulty) - can also partly explain 
1 these contradictory findings, as some studies have reported differential benefits on tasks that varied either

2 in cognitive type $[19,42]$ or task difficulty level $[26,27]$. Yet, the current findings demonstrated rather

3 consistent benefits of illuminance manipulation on relative difficult executive function, but not no

4 significant effects on easier sustained attention. Although speed improvement was partially found on

5 conflict monitoring (only for inconsistent trials), it was noted that incongruent Flanker trials could be more difficult to perform than congruent trials in which no or minimal demanding of executive conflict

7 occurred. One recent study by Huiberts et al. [27] suggested that the benefits of an illuminance manipulation were evidenced on difficult but not on easy level of working memory task as assessed with neither BDST task nor relatively easy PVT task. Together with the current findings, these results suggest that the NIF effect of an illuminance manipulation is more strongly moderated by the difficulty level of task itself than the type of task. Nevertheless, additional studies are required to establish the potential moderating effect of the difficulty of task for various cognitive domains modulate on the diurnal effects of light exposure on cognitive functioning.

In addition to task performance, the current results did not reveal individual or combined benefits of high illuminance level and CCT level on participants' feeling of alertness. This result is comparable to two recent studies that revealed participants' subjective sleepiness also remained unaffected after 50 minutes exposure to $1000 \mathrm{~lx}$ vs. $200 \mathrm{~lx}$ [27] as well to $6000 \mathrm{~K}$ vs. $2700 \mathrm{~K}$ light [18]. In addition, these results are in line with two very recent studies investigating dose-response relationship between alertness and illuminance during daytime $[44,45]$. These studies revealed that daytime exposure to more intense light, at least for one hour of exposure, may not systematically benefit alertness or executive functioning. Moreover, as mentioned above, studies reporting positive effects of CCT level on daytime alertness employed either longer exposure periods or extremely high CCT levels $[54,55,75,76]$. In the current 
1 study, participants showed overall deterioration of subjective alertness during the test session, such that

larger increments in sleepiness occurred in the second as well as the third measurement block during the experimental phase (i.e., about 38 and 50 minutes after light manipulation onset), but regardless of light condition. This gradually increased sleepiness could be the result of the sustained cognitive load during the test session which may have induced mental fatigue. Together, the current findings underline the fact that exposure to higher illuminance or CCT level lighting does not always induce a positive effect on subjective alertness during daytime, at least not within 50 minutes.

In contrast to effects on alertness, results on subjective mood revealed significant effects of both illuminance and CCT levels. Participants' negative mood significantly decreased after 50 minutes of exposure to high vs. low illuminance (1000 lx vs. 100 lx) level, or to low vs. high CCT (3000 K vs. 6500 K) level. This finding was in line with earlier studies that reported positive effects of illuminance level on subjective mood [77], as well studies suggesting participants have less positive affect and more negative affect under high vs. low CCT (6000 K vs. $2700 \mathrm{~K}$ ) conditions during daytime [18]. We should acknowledge that the changes in negative mood were relatively modest, particularly for the intensity manipulation. Whether this has practical relevance may depend on the specific application domain, but, perhaps more importantly, the question whether these effects gradually dissipate, are persistent, or even increase with exposure time should be answered first, before we recommend people select more bright or warm light at work or at home to relieve their negative mood.

Meanwhile, the effect of light on lighting appraisals was also investigated at end of the experimental session. The data revealed that lower CCT level $(3000 \mathrm{~K})$ was subjectively perceived as more beneficial for their subjective mood, which is consistent with the effect of CCT on subjective mood as assessed with the PANAS. Light of 1000 lx vs. 100 lx was reported to be brighter and to benefit their task performance, 
1 but also less soft and less comfortable in the current study. This underlines the point that multiple

2

indicators including subjective experience and objective performance should be taken account when applying these laboratory findings in actual working environment.

The mechanism underlying the relationship between diurnal light exposure and cognitive performance is still unclear, and the effects may operate through both the NIF and image forming system (e.g., [37]). While melatonin might play an important role at night, melatonin level is minimal during the subjective day for well-entrained individuals. This means that there is little room for suppression of melatonin by ipRGCs activation [78,79]. Nevertheless, multiple alternative hypotheses have been generated to speculate on the underlying mechanism of light-induced regulation of alertness and cognition. In addition to light's effects via regulation of the 24-h circadian rhythm, one possible mechanism is the light-induced activation of cortical networks involved in cognitive processing (i.e. the dorso-lateral prefrontal cortex, intraparietal sulcus (IPS) and superior parietal lobule, middle frontal gyrus, supramarginal gyrus and IPS) and subcortical networks (i.e. alertness-related brainstem, thalamus), such as impacting arousal, attention, and memory [17,32-36]. Moreover, lighting appraisals or expectations regarding effects of ambient light $[37,38]$ as well as the regulation of mood-related brain regions (amygdala and hippocampus) [17,80] have been proposed to contribute to the potential effects of light on alertness and cognition. The current results on mood and appraisals do not provide support for the potential mediating role of positive appraisals, beliefs and/or affect in the effects of light level or spectrum on alertness and cognition. We did not assess brain activity, and additional research is required to determine which brain regions play a crucial role in the diurnal effects of light on alertness and cognition. 
1 four tasks were presented in a fixed order (with two versions), and the PVT task was always presented

first, which may have introduced a confounded change in arousal or mental fatigue across the different tasks. Moreover, effects of light might be more pronounced after longer exposure (e.g., 30 minutes) $[19,20]$. Secondly, although we measured participants' prior mental state, self-reported sleep duration and chronotype; we did not employ objective measures for participants' night sleep (i.e., sleep-wake pattern and quality) by means of, for instance, actigraphy on the day(s) before the experiment day. In addition, the performance tasks employed in the current study were visual tasks suggesting that we cannot eliminate potential effects of the lighting conditions on visual task performance. Having said this, the task stimuli were presented in such a way that it is unlikely that the conditions impeded the visibility of the task. The potential moderating role of task modality on the impact of light on alertness is, at least to our knowledge, as yet unknown. Furthermore, it should be noted that there were quite substantial differences in the timing of the lighting manipulations between participants in the current study. A few recent studies have revealed time-of-day dependent moderations in the effects of illuminance (e.g., $[20,80])$ and CCT (e.g., [18]) in effects of light on daytime performance. The current study, however, did not test time-of-day dependent moderations due to the relatively low number of observations per time interval for each condition and because of the fact that this was not purpose of the current study. Thus additional research is required to test time-of-day dependency of the individual and combined effect of illuminance and CCT on various cognitive performance tasks.

\section{Conclusion}

In sum, exposure to high vs. low illuminance selectively benefited task performance, and decreased participants' negative mood. Participants' reaction speed in response inhibition and conflict inhibition, 
1 and accuracy in working memory were significantly enhanced with $1000 \mathrm{~lx}$ compared to $100 \mathrm{~lx}$ (at eye

2 level) condition, while the remaining performance indicators showed no statistically significant effects.

3 The current findings revealed that the manipulation of CCT elicited no statistically significant benefits on

4 subjective sleepiness and task performance, but did affect participants' negative mood. It is important, in this respect, to note that the activation of the ipRGCs of the CCT manipulation we employed was substantially smaller than that of our illuminance manipulation.

Our findings contribute to the current studies suggesting that manipulation of office light during daytime does have the potential to optimal employees' subjective responses and ongoing task performance. Yet, in order to define optimal lighting settings, additional research is required.

\section{Declaration of interest}

The author declared no potential conflicts of interest with respect to the research, authorship, and/or publication of this article.

\section{Funding}

This work was supported by the National Key Research and Development Program of China (No. 2016YFB0401202), National Natural Science Foundation of China (Grant No. U1501244, 51561135014), Guangdong Innovative Research Team Program (No. 2013C102), Science and Technology project of Guangdong Province (No.2015B090913004), a program co-financed by Philips Lighting,

\section{References}

[1] D.M. Berson, F.A. Dunn, M. Takao, Phototransduction by retinal ganglion cells that set the 
circadian clock, Science. 295 (2002) 1070-1073.

[2] M.S. Freedman, R.J. Lucas, B. Soni, M. von Schantz, M. Muñoz, Z. David-Gray, R. Foster, Regulation of mammalian circadian behavior by non-rod, non-cone, ocular photoreceptors, Science. 284 (1999) 502-504.

[3] I. Provencio, I.R. Rodriguez, G. Jiang, W.P. Hayes, E.F. Moreira, M.D. Rollag, A novel human opsin in the inner retina, J. Neurosci. 20 (2000) 600-605.

[4] S. Hattar, H.W. Liao, M. Takao, D.M. Berson, K.W. Yau, Melanopsin-containing retinal ganglion cells: Architecture, projections, and intrinsic photosensitivity, Science. 295 (2002) 1065-1070.

[5] P. Badia, B. Myers, M. Boecker, J. Culpepper, J.R. Harsh, Bright light effects on body temperature, alertness, EEG and behavior, Physiol. Behav. 50 (1991) 583-588.

[6] C. Lafrance, M. Dumont, P. Lespérance, C. Lambert, Daytime vigilance after morning bright light exposure in volunteers subjected to sleep restriction, Physiol. Behav. 63 (1998) 803-810.

[7] T.L. Sletten, V.L. Revell, B. Middleton, K.A. Lederle, D.J. Skene, Age-related changes in acute and phase-advancing responses to monochromatic light, J. Biol. Rhythms. 24 (2009) 73-84.

[8] J.M. Zeitzer, D.J. Dijk, R.E. Kronauer, E.N. Brown, C.A. Czeisler, Sensitivity of the human circadian pacemaker to nocturnal light: Melatonin phase resetting and suppression, J. Physiol. $526(2000)$ 695-702.

[9] C. Cajochen, D.P. Brunner, K. Kräuchi, P. Graw, A. Wirz-Justice, EEG and subjective sleepiness during extended wakefulness in seasonal affective disorder: Circadian and homeostatic influences, Biol. Psychiatry. 47 (2000) 610-617.

[10] C. Cajochen, M. Münch, S. Kobialka, K. Kräuchi, R. Steiner, P. Oelhafen, S. Orgül, A. Wirz-Justice, High Sensitivity of Human Melatonin, Alertness, Thermoregulation, and Heart Rate to Short Wavelength Light, J. Clin. Endocrinol. Metab. 90 (2005) 1311-1316.

[11] S.L. Chellappa, R. Steiner, P. Blattner, T. Gotz, C. Cajochen, Non-visual effects of light on melatonin, alertness and cognitive performance: Can blue-enriched light keep us alert?, PLoS One. 6 (2011) e16429.

[12] L. Sahin, B.M. Wood, B. Plitnick, M.G. Figueiro, Daytime light exposure: Effects on biomarkers, measures of alertness, and performance, Behav. Brain Res. 274 (2014) 176-185.

[13] M.G. Figueiro, M.S. Rea, J.D. Bullough, Circadian effectiveness of two polychromatic lights in 
suppressing human nocturnal melatonin, Neurosci. Lett. 406 (2006) 293-297.

[14] M.G. Figueiro, J.D. Bullough, A. Bierman, C.R. Fay, M.S. Rea, On light as an alerting stimulus at night, Acta Neurobiol. Exp. 67 (2007) 171-178.

[15] M.G. Figueiro, R. Nagare, L.L.A. Price, Non-visual effects of light: How to use light to promote circadian entrainment and elicit alertness, Light. Res. Technol. 50 (2018) 38-62.

[16] J.L. Souman, A.M. Tinga, S.F. Te Pas, R. van Ee, B.N.S. Vlaskamp, Acute alerting effects of light: A systematic literature review, Behav. Brain Res. 337 (2018) 228-239.

[17] G. Vandewalle, P. Maquet, D.J. Dijk, Light as a modulator of cognitive brain function, Trends Cogn. Sci. 13 (2009) 429-438.

[18] K.C.H.J. Smolders, Y.A.W. de Kort, Investigating daytime effects of correlated colour temperature on experiences, performance, and arousal, J. Environ. Psychol. 50 (2017) 80-93.

[19] K.C.H.J. Smolders, Y.A.W. de Kort, Bright light and mental fatigue: Effects on alertness, vitality, performance and physiological arousal, J. Environ. Psychol. 39 (2014) 77-91.

[20] K.C.H.J. Smolders, Y.A.W. de Kort, P.J.M. Cluitmans, A higher illuminance induces alertness even during office hours: Findings on subjective measures, task performance and heart rate measures, Physiol. Behav. 107 (2012) 7-16.

[21] L. Tonetti, M. Fabbri, A. Erbacci, M. Filardi, M. Martoni, V. Natale, Effects of dawn simulation on attentional performance in adolescents, Eur. J. Appl. Physiol. 115 (2015) 579-587.

[22] J. Phipps-Nelson, J.R. Redman, D.J. Dijk, S.M. Rajaratnam, Daytime exposure to bright light, as compared to dim light, decreases sleepiness and improves psychomotor vigilance performance, Sleep. 26 (2003) 695-700.

[23] M. Van De Werken, M.C. Giménez, B. De Vries, D.G.M. Beersma, E.J.W. Van Someren, M.C.M. Gordijn, Effects of artificial dawn on sleep inertia, skin temperature, and the awakening cortisol response, J. Sleep Res. 19 (2010) 425-435.

[24] M. Rüger, M.C.M. Gordijn, D.G.M. Beersma, B. de Vries, S. Daan, Time-of-day-dependent effects of bright light exposure on human psychophysiology: comparison of daytime and nighttime exposure, Am. J. Physiol. Integr. Comp. Physiol. 290 (2006) R1413-R1420.

[25] Á. Correa, A. Barba, F. Padilla, Light effects on behavioural performance depend on the individual state of vigilance, PLoS One. 11 (2016) e0164945.

[26] L.M. Huiberts, K.C.H.J. Smolders, Y.A.W. de Kort, Shining light on memory: Effects of bright 
light on working memory performance, Behav. Brain Res. 294 (2015) 234-245.

[27] L.M. Huiberts, K.C.H.J. Smolders, Y.A.W. de Kort, Non-image forming effects of illuminance level: Exploring parallel effects on physiological arousal and task performance, Physiol. Behav. 164 (2016) 129-139.

[28] J.I.N.Y. Park, B.-K. Min, Y.-C. Jung, H. Pak, Y.-H. Jeong, E. Kim, Illumination influences working memory: An EEG study, Neuroscience. 247 (2013) 386-394.

[29] G. Vandewalle, S. Gais, M. Schabus, E. Balteau, J. Carrier, A. Darsaud, V. Sterpenich, G. Albouy, D.J. Dijk, P. Maquet, Wavelength-dependent modulation of brain responses to a working memory task by daytime light exposure, Cereb. Cortex. 17 (2007) 2788-2795.

[30] D.-J. Dijk, J.F. Duffy, E.J. Silva, T.L. Shanahan, D.B. Boivin, C.A. Czeisler, Amplitude reduction and phase shifts of melatonin, cortisol and other circadian rhythms after a gradual advance of sleep and light exposure in humans, PLoS One. 7 (2012) e30037.

[31] T.H. Monk, D.J. Buysse, B.D. Billy, K.S. Kennedy, D.J. Kupfer, The effects on human sleep and circadian rhythms of 17 days of continuous bedrest in the absence of daylight, Sleep. 20 (1997) $858-864$.

[32] G. Vandewalle, E. Balteau, C. Phillips, C. Degueldre, V. Moreau, V. Sterpenich, G. Albouy, A. Darsaud, M. Desseilles, T.T. Dang-Vu, P. Peigneux, A. Luxen, D.-J. Dijk, P. Maquet, Daytime Light Exposure Dynamically Enhances Brain Responses, Curr. Biol. 16 (2006) 1616-1621.

[33] E. Rautkylä, M. Puolakka, L. Halonen, Alerting effects of daytime light exposure - a proposed link between light exposure and brain mechanisms, Light. Res. Technol. 44 (2011) 238-252.

[34] K.M. Stephenson, C.M. Schroder, G. Bertschy, P. Bourgin, Complex interaction of circadian and non-circadian effects of light on mood: Shedding new light on an old story, Sleep Med. Rev. 16 (2012) 445-454.

[35] A.S. Fisk, S.K.E. Tam, L.A. Brown, V. V Vyazovskiy, D.M. Bannerman, S.N. Peirson, Light and Cognition: Roles for Circadian Rhythms, Sleep, and Arousal, Front. Neurol. 9 (2018) 56.

[36] R. Lok, K.C.H.J. Smolders, D.G.M. Beersma, Y.A.W. de Kort, Light, Alertness, and Alerting Effects of White Light: A Literature Overview, J. Biol. Rhythms. 33 (2018) 589-601.

[37] Y.A.W. de Kort, J.A. Veitch, From blind spot into the spotlight: Introduction to the special issue 'Light, lighting, and human behaviour,' J. Environ. Psychol. 39 (2014) 1-4.

[38] J.A. Veitch, M.G.M. Stokkermans, G.R. Newsham, Linking lighting appraisals to work 
behaviors, Environ. Behav. 45 (2013) 198-214.

[39] C. Cajochen, Alerting effects of light, Sleep Med. Rev. 11 (2007) 453-464.

[40] S.W. Lockley, E.E. Evans, F.A. Scheer, G.C. Brainard, C.A. Czeisler, D. Aeschbach, Short-wavelength sensitivity for the direct effects of light on alertness, vigilance, and the waking electroencephalogram in humans, Sleep. 29 (2006) 161-168.

[41] V. Gabel, M. Maire, C.F. Reichert, S.L. Chellappa, C. Schmidt, V. Hommes, A.U. Viola, C. Cajochen, Effects of artificial dawn and morning blue light on daytime cognitive performance, well-being, cortisol and melatonin levels, Chronobiol. Int. 30 (2013) 988-997.

[42] V. Gabel, M. Maire, C.F. Reichert, S.L. Chellappa, C. Schmidt, V. Hommes, C. Cajochen, A.U. Viola, Dawn simulation light impacts on different cognitive domains under sleep restriction, Behav. Brain Res. 281 (2015) 258-266.

[43] N. Santhi, S.N. Archer, M. Gimenez, L.J.M. Schlangen, D.J. Dijk, Morning sleep inertia in alertness and performance: Effect of cognitive domain and white light conditions, PLoS One. 8 (2013) e79688.

[44] R. Lok, T. Woelders, M.C.M. Gordijn, R.A. Hut, D.G.M. Beersma, White Light During Daytime Does Not Improve Alertness in Well-rested Individuals, J. Biol. Rhythms. 33 (2018) 637-648.

[45] K.C.H.J. Smolders, S.T. Peeters, I.M.L.C. Vogels, Y.A.W. de Kort, Investigation of Dose-Response Relationships for Effects of White Light Exposure on Correlates of Alertness and Executive Control during Regular Daytime Working Hours, J. Biol. Rhythms. 33 (2018) $649-661$.

[46] V. Leichtfried, M. Mair-Raggautz, V. Schaeffer, A. Hammerer-Lercher, G. Mair, C. Bartenbach, M. Canazei, W. Schobersberger, Intense illumination in the morning hours improved mood and alertness but not mental performance, Appl. Ergon. 46 (2015) 54-59.

[47] B.K. Min, Y.C. Jung, E. Kim, Y.P. Jin, Bright illumination reduces parietal EEG alpha activity during a sustained attention task, Brain Res. 1538 (2013) 83-92.

[48] M.W. Hankins, S.N. Peirson, R.G. Foster, Melanopsin: An exciting photopigment, Trends Neurosci. 31 (2008) 27-36.

[49] G.C. Brainard, J.P. Hanifin, J.M. Greeson, B. Byrne, G. Glickman, E. Gerner, M.D. Rollag, Action spectrum for melatonin regulation in humans: Evidence for a novel circadian photoreceptor, J. Neurosci. 21 (2001) 6405-6412. 
1 [50] K. Thapan, J. Arendt, D.J. Skene, An action spectrum for melatonin suppression: Evidence for a novel non-rod, non-cone photoreceptor system in humans, J. Physiol. 535 (2001) 261-267.

[51] G.C. Brainard, J.P. Hanifin, Photons, clocks, and consciousness, J. Biol. Rhythms. 20 (2005) $314-325$.

[52] S.A. Rahman, E.E. Flynn-Evans, D. Aeschbach, G.C. Brainard, C.A. Czeisler, S.W. Lockley, Diurnal spectral sensitivity of the acute alerting effects of light, Sleep. 37 (2014) 271-281.

[53] O. Keis, H. Helbig, J. Streb, K. Hille, Influence of blue-enriched classroom lighting on students' cognitive performance, Trends Neurosci. Educ. 3 (2014) 86-92.

[54] A.U. Viola, L.M. James, L.J.M. Schlangen, D.J. Dijk, Blue-enriched white light in the workplace improves self-reported alertness, performance and sleep quality, Scand. J. Work. Environ. Health. 34 (2008) 297-306.

[55] P.R. Mills, S.C. Tomkins, L.J.M. Schlangen, The effect of high correlated colour temperature office lighting on employee wellbeing and work performance, J. Circadian Rhythms. 5 (2007) 2.

[56] R.J. Lucas, S.N. Peirson, D.M. Berson, T.M. Brown, H.M. Cooper, C.A. Czeisler, M.G. Figueiro, P.D. Gamlin, S.W. Lockley, J.B. O’Hagan, Measuring and using light in the melanopsin age, Trends Neurosci. 37 (2014) 1-9.

[57] R.J. Lucas, G.S. Lall, A.E. Allen, T.M. Brown, How rod, cone, and melanopsin photoreceptors come together to enlighten the mammalian circadian clock, Prog. Brain Res. 199 (2012) 1-18.

[58] M. Spitschan, S. Jain, D.H. Brainard, G.K. Aguirre, Opponent melanopsin and S-cone signals in the human pupillary light response, Proc. Natl. Acad. Sci. 111 (2014) 15568-15572.

[59] T. Woelders, T. Leenheers, M.C.M. Gordijn, R.A. Hut, D.G.M. Beersma, E.J. Wams, Melanopsin- and L-cone-induced pupil constriction is inhibited by S- and M-cones in humans, Proc. Natl. Acad. Sci. 115 (2018) 792-797.

[60] D.M. Dacey, H.W. Liao, B.B. Peterson, F.R. Robinson, V.C. Smith, J. Pokorny, K.W. Yau, P.D. Gamlin, Melanopsin-expressing ganglion cells in primate retina signal colour and irradiance and project to the LGN, Nature. 433 (2005) 749-754.

[61] A.D. Güler, J.L. Ecker, G.S. Lall, S. Haq, C.M. Altimus, H.W. Liao, A.R. Barnard, H. Cahill, T.C. Badea, H. Zhao, Melanopsin cells are the principal conduits for rod-cone input to non-image-forming vision, Nature. 453 (2008) 102-105.

[62] M.S. Rea, M.G. Figueiro, J.D. Bullough, A. Bierman, A model of phototransduction by the 
human circadian system, Brain Res. Rev. 50 (2005) 213-228.

[63] L. Bellia, M. Seraceni, A proposal for a simplified model to evaluate the circadian effects of light sources, Light. Res. Technol. 46 (2014) 493-505.

[64] H. Noguchi, T. Sakaguchi, Effect of illuminance and color temperature on lowering of physiological activity, Appl. Hum. Sci. J. Physiol. Anthropol. 18 (1999) 117-123.

[65] D. Goldberg, K. Bridges, P. Duncan-Jones, D.A. Grayson, Detecting anxiety and depression in general medical settings, BMJ. 297 (1988) 897-899.

[66] D.J. Buysse, C.F. Reynolds, T.H. Monk, S.R. Berman, D.J. Kupfer, The Pittsburgh Sleep Quality Index: A new instrument for psychiatric practice and research, Psychiatry Res. 28 (1989) 193-213.

[67] T. Roenneberg, A. Wirzjustice, M. Merrow, Life between clocks: Daily temporal patterns of human chronotypes, J. Biol. Rhythms. 18 (2003) 80-90.

[68] T. Åkerstedt, M. Gillberg, Subjective and objective sleepiness in the active individual, Int. J. Neurosci. 52 (1990) 29-37.

[69] D. Watson, L.A. Clark, A. Tellegen, Development and validation of brief measures of positive and negative affect: The PANAS scales, J. Pers. Soc. Psychol. 54 (1988) 1063-1070.

[70] D.F. Dinges, J.W. Powell, Microcomputer analyses of performance on a portable, simple visual RT task during sustained operations, Behav. Res. Methods, Instruments, Comput. 17 (1985) $652-655$.

[71] L.E. Hartstein, M.T. Durniak, R.F. Karlicek Jr, N.E. Berthier, A comparison of the effects of correlated colour temperature and gender on cognitive task performance, Light. Res. Technol. 50 (2018) 1057-1069.

[72] B.A. Eriksen, C.W. Eriksen, Effects of noise letters upon the identification of a target letter in a nonsearch task, Percept. Psychophys. 16 (1974) 143-149.

[73] A. Feinstein, R. Brown, M. Ron, Effects of practice of serial tests of attention in healthy subjects, J. Clin. Exp. Neuropsychol. 16 (1994) 436-447.

[74] J.E. Flynn, T.J. Spencer, O. Martyniuk, C. Hendrick, Interim study of procedures for investigating the effect of light on impression and behavior, J. Illum. Eng. Soc. 3 (1973) 87-94.

[75] I. Iskra-Golec, L. Smith, Bright light effects on ultradian rhythms in performance on hemisphere-specific tasks, Appl. Ergon. 42 (2011) 256-260. 
1 [76] T. Partonen, J. Lönnqvist, Bright light improves vitality and alleviates distress in healthy people,

2

3

4

5

6 J. Affect. Disord. 57 (2000) 55-61.

[77] R.A. Baron, M.S. Rea, S.G. Daniels, Effects of indoor lighting (illuminance and spectral distribution) on the performance of cognitive tasks and interpersonal behaviors: The potential mediating role of positive affect, Motiv. Emot. 16 (1992) 1-33.

[78] C. Cajochen, K. Kräuchi, A. Wirz-Justice, Role of Melatonin in the Regulation of Human Circadian Rhythms and Sleep, J. Neuroendocrinol. 15 (2003) $432-437$.

[79] C. Gronfier, K.P. Wright, R.E. Kronauer, C.A. Czeisler, Entrainment of the human circadian pacemaker to longer-than-24-h days, Proc. Natl. Acad. Sci. 104 (2007) 9081-9086.

[80] G. Vandewalle, S. Schwartz, D. Grandjean, C. Wuillaume, E. Balteau, C. Degueldre, M. Schabus, C. Phillips, A. Luxen, D.J. Dijk, Spectral quality of light modulates emotional brain responses in humans, Proc. Natl. Acad. Sci. 107 (2010) 19549-19554. 


\section{Highlights}

Manipulation of correlated color temperature of office light elicited no statistically significant benefits on subjective alertness and task performance

Exposure to high vs. low illuminance rendered subtle benefits on participants' mood and selectively improved performance

Diurnal non-visual effects of office light would depend on task type and melanopic activation 